\title{
PSICOTERAPIA DE GRUPO COM PACIENTES DIABÉTICOS E HIPERTENSOS EM CENTROS DE SAÚDE PÚBLICA
}

\section{GROUP PSYCHOTHERAPY WITH DIABETIC AND HYPERTENSES PATIENTS IN PUBLIC HEALTH CENTERS}

\author{
Claudia Lins CARDOSO
}

\begin{abstract}
RESUMO
Este artigo descreve a experiência clínica, através da psicoterapia de grupo com pacientes portadores de diabetes e hipertensão arterial, em dois Centros de Saúde Pública da região metropolitana de Belo Horizonte (MG). Uma reflexão sobre as atividades desenvolvidas revela que o resultado foi positivo, tanto para os pacientes, que demonstraram alguma melhora no quadro clínico e no emocional, quanto para os alunos envolvidos no trabalho, que tiveram a oportunidade de exercer o atendimento clínico num contexto institucional público, cujas características diferem bastante do atendimento em consultório particular.
\end{abstract}

Palavras chave: psicoterapia de grupo; hipertensão arterial; diabetes.

\begin{abstract}
This article describes the clinical experience of group psychotherapy on patients suffering from diabetes and arterial hypertension who frequented two health centers in Belo Horizonte, MG, Brazil. A reflection on activities developed shows positive results, both for patients, who increased their clinical and emotional state, and for students, who could develop a clinical experience in a public institution, whose caracteristics are much more different than private office.
\end{abstract}

Key-words: group psychotherapy; arterial hypertension; diabetes.

$\mathrm{Na}$ atualidade, entre os profissionais da saúde, está cada vez mais consolidada a postura de apreender o homem como um organismo unificado, onde mente e corpo, comportamento e sentimento são entendidos como aspectos absolutamente interligados. Diversos estudos científicos têm comprovado que fatores biológicos, psicológicos e sociais interagem de diferentes modos e proporções na gênese de qualquer enfermidade.

(1) Professora Assistente do Departamento de Psicologia da Faculdade de Filosofia e Ciências Humanas (FAFICH) da UFMG 
Campos (1992a) faz uma relação detalhada entre as emoções e as manifestações somáticas. Propõe que as emoções possuem duas funções básicas: uma de avaliar a experiência e outra de expressar o resultado de tal avaliação, o que se dá tanto em termos de sinais emocionais (sorrir, chorar, gritar, etc.) quanto de ações emocionais (brigar, fugir, comer,etc.). Esse autor identifica o sistema límbico (incluindo o hipotálamo, coordenador das diversas funções neurovegetativas) como a sede das emoções e elo entre o somático e o emocional, na medida em que aquele órgão seria o responsável pela avaliação dos estímulos captados e pela resposta a estes, deflagrando-a pelos vários órgãos do organismo.

$\mathrm{Na}$ experiência humana, todo esse processo estaria entremeado pela capacidade de perceber a própria experiência e de colocá-la em palavras. Em seu trabalho, Campos (op. cit.) atribui a essa capacidade de falar (discutir, refletir, etc.) uma estratégia mais elaborada de enfrentamento das situações vivenciadas. Assim, quando falar não é possível, a tendência do organismo humano será a de fazer uso de outros modos de enfrentamento, tais como: mental (fantasiar, racionalizar, etc.), emocional (chorar, culpar-se, etc), atitudinal (isolar-se, arriscar-se, etc.), aditivo (comer, beber, drogarse, etc.) e somático (adoecer). Emsuma,"quanto menos os mecanismos mentais ou cognitivos de falar e agir estiverem funcionando, tanto mais o somático será utilizado" (Campos, 1992a, p. 239).

Meio Filho (1997) afirma que de um a dois terços dos pacientes que procuram ambulatórios médicos ou serviços de emergência apresentam queixas de sintomas físicos sem qualquer evidência de distúrbio fisiológico. Em vez disso, parece que tais pacientes sofrem de manifestações hipocondríacas, histéricas com somatizações, onde o componente psicológico está comprovadamente presente. Mesmo as pessoas que se sentem doentes e realmente padecem de algum comprometimento físico sofrem influência do fator psicológico, visto que a vulnerabilidade ante a doença sempre ameaça de alguma forma a integridade do indivíduo. Com isso, aquele autor sustenta que todo paciente somático possui um comprometimento psicológico em maior ou menor grau, o que justificaria o atendimento psicológico em associação ao tratamento médico.

Resultados semelhantes foram obtidos numa pesquisa recente realizada pela Organização Mundial de Saúde em quatorze países (inclusive no Brasil), com pessoas que buscavam atendimento médico devido a sintomas físicos. Foi evidenciado que a quarta parte da amostra sofria, na verdade, de distúrbios mentais.

Ismael (1998) ressalta que também o tratamento pode afetar o equilíbrio psicológico do indivíduo, visto que muitas vezes requer o ajustamento a um novo meio físico e social ou implica na manipulação do paciente por pessoas desconhecidas. Sem dúvida, o atendimento psicológico, semelhante ao atendimento médico, precisa levar em consideração os aspectos da clientela a ser atendida para que seja possível alcançar seus objetivos.

Alguns trabalhos desenvolvidos no país oferecem contribuição interessante sobre a experiência do atendimento psicológico realizado em instituição de saúde: Amaral \& Yashida, 1993; Carvalho, 1997; Silva, 1998; Silva Filho, 1996.

Sendo o homem um ser de relação, possui em sua natureza o movimento espontâneo de juntar-se a outros de sua espécie, de modo tal que sua sobrevivência só é possível graças às interações que estabelece ao longo de sua vida com outros seres humanos. Além da família, que é o primeiro grupo natural ao qual pertence, o indivíduo passa a maior parte de sua vida interagindo com os mais variados tipos de grupos. Como tal, é possível afirmar que o contato faz parte da essência de nossa natureza. Em outras palavras, ao contrário das demais espécies animais, o homem precisa do contato com seus semelhantes para se tornar homem. 
Com base nessa perspectiva, a psicoterapia de grupo tem sido considerada por vários autores uma importante modalidade de atendimento psicológico, visto que o grupo possibilita uma diversidade de interações entre seus membros, o que, no processo psicoterapêutico, pode servir como um instrumento de autoconhecimento e crescimento

Rogers (1987) ressaltou como característica dos grupos o clima de segurança psicológica, o encorajamento à expressão de sentimentos e a conseqüente resposta por parte dos componentes do grupo, o que torna a psicoterapia grupal um contexto propício ao crescimento pessoal.

Ribeiro (1994) sustenta que a dinâmica da psicoterapia de grupo propicia uma circulação de informações bastante favorável, havendo troca de vivências, modelos e papéis, onde os próprios componentes se ajudam mutuamente. Isso significa que a experiência grupal funciona como campo de forças onde cada um atua sobre o outro. O grupo se constitui, então, numa unidade em permanente reflexão da realidade interna e externa de seus membros, levando cada um deles e o grupo como um todo a uma maior conscientização de si mesmo e a um modo diferente de experienciar suas vivências emocionais.

Yalom (1995) propôs uma lista com onze fatores terapêuticos que, segundo ele, promovem a eficácia da psicoterapia de grupo: instilação de esperança, universalidade, oferecimento de informações, altruísmo, desenvolvimento de técnicas de socialização, comportamento imitativo, catarse, reedição corretiva do grupo familiar primário, fatores existenciais, coesão do grupo e aprendizagem interpessoal.

Ulman (1996) ressalta que, dos fatores propostos por Yalom (1995), a transmissão de informações, referente ao aconselhamento ou orientação direta sobre um problema específico, a catarsee a universalidade (a constatação dos pacientes de que eles não são os únicos a terem certo tipo de problemas),têm importância especial em grupos com pacientes fisicamente enfermos, mais do que em grupos regulares de psicoterapia. Os fatores curativos de instilação de esperança, aprendizagem social e comportamento imitativo também se constituem em fatores degrande relevânciano processopsicoterapêutico dos pacientes daquele tipo de grupos.

Quanto à aplicação da psicoterapia de grupo junto a pacientes portadores de doenças orgânicas, o trabalho desenvolvido por Melo Filho (1986) evidenciou seus efeitos benéficos como método de prevenção e tratamento de pacientes com hipertensão e portadores de doenças psicossomáticas, pois configura-se num espaço livre para a expressão de sentimentos, emoções e reações, onde o grupo funciona como um facilitador do processo.

Alguns estudos fazem reflexões interessantes sobre a experiência com grupos psicoterapêuticos em instituições de saúde pública no Brasil, discorrendo sobre algumas características e dificuldades deste tipo de atuação: Boarini, 1989, Carvalho \& Silva, 1990.

Campos (1992b), no relato de sua experiência, propõe dois objetivos daação do terapeuta junto a pacientes psicossomáticos podendo ser resumidos, basicamente,em: facilitar a expressão de sentimentos e oferecer apoio para que a pessoa possa descobrir novas formas de enfrentamento (verbais, cognitivos ou comportamentais), em vez de reagir corporalmente a uma determinada situação de vida.

\section{Aspectos Filosóficos da Gestalt-terapia}

Embora a literatura sobre grupoterapia ofereça uma grande diversidade de propostas teóricas e técnicas, faremos uma breve exposição sobre os principais aspectos da psicoterapia de grupo segundo os alicerces teóricos e filosóficos propostos pela Gestalt-terapia. Esta foi a abordagem adotada ao longo dos atendimentos psicoterapêuticos, por apresentar objetivos capazes de atender às necessidades básicas dos pacientes fisicamente enfermos, conforme apresentadas na literatura. 
Numa perspectiva bastante resumida, a Gestalt-terapia pode ser descrita como uma abordagem psicoterapêutica de base existencial-fenomenológica, cujo objetivo principal é ampliar o potencial da pessoa através da conscientização plena (awareness) de si mesma, do ambiente em que se encontra, da responsabilidade por suas escolhas existenciais e da habilidade para o contato com o meio. Busca, sobretudo, favorecer a tomada de consciência da experiência atual (aqui-e-agora),e reabilitar a percepção emocional e corporal através do método fenomenológico, o que traz implícito o pressuposto de que quanto maior for o nível de autopercepção, maior (e melhor) será o nível de funcionamento da pessoa (Ginger \& Ginger, 1995; Perls, Heferline \& Goodman, 1997).

A fundamentação filosófica que dá sustentação às propostas da Gestalt-terapia se constitui a partir de três pilares básicos: o humanismo, o existencialismo e a fenomenologia.

A Gestalt-terapia é congruente com a proposta do humanismo de valorização do ser humano, entendendo no processo psicoterapêutico a importância de ter como foco a experimentação das potencialidades da pessoa, de modo que esta seja capaz de desfrutar delas tendo a si mesma como referencial, bem como o reconhecimento de seus limites. Com isso, a pessoa estaria apta a vivenciar de forma plena e integrada o seu agir, pensar e sentir (Martins, 1995; Ribeiro, 1985).

Os pressupostos do existencialismo repercutem de modo considerável na prática da Gestalt-terapia. Ao considerar o homem como um ser particular, consciente, responsável e livre para construir seu projeto existencial, esta abordagem busca levar a pessoa a tomar conhecimento de seu projeto de vida, da forma como ele vem sendo realizado, do desejo e possibilidade de levá-lo adiante ou de mudá-lo. Tal reflexão se dá a partir do próprio referencial da pessoa, de acordo com seu potencial e respeitando seus limites, afim deque ela possa funcionar de modo mais integrado consigo mesma e com o mundo (Ginger \& Ginger, 1995; Ribeiro, 1985).

Assim como a fenomenologia, a Gestaltterapia considera a possibilidade de haver uma discrepância entre a realidade em si e aquela que é experimentada pela pessoa, pois ao ser tocado pela realidade, a percepção que tem dela pode sofrer um viés de sua história pessoal, abrindo a possibilidade de toda uma gama de significados a partir de seu próprio referencial. Dessa forma, apoiada em seu pilar fenomenológico, prioriza-se a experiência vivida pelo cliente, tal como ele a percebe em sua experiência imediata, enfatizando o como ele está vivenciando aquela experiência. As explicações sobre o que ocorre em tal situação têm importânciasecundária (Martins, 1995; Ribeiro, 1985).

\section{A Psicoterapia de Grupo na Abordagem Gestáltica}

Além da fundamentação filosófica baseada no humanismo, existencialismo e fenomenologia, a elaboração de um modelo conceitual de grupo e de processos grupais coerente com as proposições da Gestalt-terapia passa necessariamente pelas premissas da Psicologia da Gestalt, Teoria de Campo e Teoria Organísmica, visto que estas oferecem uma compreensão da dinâmica interrelacional de grupos complexos, sua organização, regulação e direção.

Inicialmente, a Psicologia da Gestalt oferece à Gestalt-terapia a noção básica de gestalt, entendida como uma configuração cuja totalidade é muito maior que a mera soma das partes, pois inclui também a inter-relação existente entre elas. Todo campo perceptivo se diferencia em um fundo e uma figura ou forma que sobressai daquele. Não podemos distinguir a figura sem um fundo. A Gestalt se interessa por ambos, ma s obretudo por sua interrelação (Ginger \& Ginger, 1995). 
Do ponto de vista da prática clínica, o grupo é visto como uma gestalt, como um poderoso campo de forças que interligam os membros do grupo e norteiam sua interação, criando uma realidade dinâmica que será percebida e modificada segundo o processo individual de cada um (Ribeiro, 1994).

A Teoria de Campo de Kurt Lewin vê a realidade como um grande campo de forças, como um todo dinâmico, concreto e limitado que se caracteriza por se constituir numa complexa rede de relações entre as partes. A análise das partes componentes desse todo permite uma descrição explicativa e sistêmica dos eventos que nele ocorrem ,ou seja, como a mudança em uma das partes altera o todo. Porém, embora tais mudanças se produzam constantemente no campo, pois se trata de uma realidade dinâmica, ele possui algo que o mantém identificável (Ribeiro, 1994; Tellegen, 1984).

No grupo psicoterapêutico, isso significa que o grupo, como um todo, é uma rede na qual cada pessoa funciona como um campo independente, mas psicodinamicamente interligado, semelhante a um subsistema, onde cada um afeta e é afetado pelo outro e pelo conjunto, criando uma matriz grupal.

Num primeiro momento, um grupo é apenas um conjunto de pessoas, ainda sem um vínculo que as integre. À medida que elas vão entrando em contato, começam a partilhar experiências, afetos, sentimentos e assim vão configurando uma matriz grupal. Esta é uma produção do grupo, contendo informações, registrando a história que se processa durante a existência do grupo, constituindo-se numa realidade dinâmica modificada a cada instante, sempre que incorpora um elemento novo. Trata- se de um constructo semelhante ao inconsciente grupal, cultura grupal ou atmosfera de grupo (Ribeiro, 1994).

O terceiro pilar sobre o qual reside a proposta de trabalho psicoterapêutico com grupos em Gestalt-terapia é a Teoria Organísmica de Kurt Goldstein. O ceme dessa teoria é a noção de que o organismo é um todo muito maior que a mera soma das partes, estando ele em constante busca de auto-realização.

Perls (1977) ilustra a influência deste modelo de Goldstein na seguinte afirmação:

"(...) a formação de uma gestalt, a emergência de necessidades, é um fenômeno biológico primário. Assim, abolimos toda a teoria do instinto e consideramos o orga-nismo simplesmente como um sistema que está em equilíbrio e que deve funcionar adequadamente. Qualquer desequilíbrio é experiência do como necessidade a ser corrigida. (...) A situação mais urgente emerge e, em qualquer caso de emergên-cia, você percebe que ela prevalece sobre qualquer outra atividade. Portanto, chegamos agora ao fenômeno mais importante $\mathrm{e}$ interessante de toda patologia: auto-regulação versus regulação externa."(p.34)

Ribeiro (1994) transporta essa perspectiva para a situação psicoterapêutica afirmando ser o grupo, composto por várias pessoas (partes), uma imensa gestalt, um campo de energias em constante busca de equilíbrio, e a multiplicidade de pessoas que o compõe funciona como fenômeno de uma unidade maior: cliente e terapeuta, cliente e grupo, figura e fundo em constante e dinâmica interação.

Greve (1996) sintetiza o trabalho do psicoterapeuta de grupo na abordagern gestáltica salientando as seguintes posturas: ênfase continuada no aqui-e-agora da experiência de cada membro do grupo; ênfase na percepção psíquica e corporal; ênfase no contato entre os membros do grupo (ao contrário de falar a respeito deles ou com eles); expressão do que está acontecendo aqui-e-agora; respeito pelas fronteiras mútuas, cuidando para não invadir outras pessoas; expressão de si mesmo; evitação do fornecimento de conselhos.

Assim, aquele autor define o foco do trabalho da psicoterapia de grupo na Gestaltterapia sobre "a percepção que os membros têm de si mesmos, o como e o que de sua existência atual, o tipo de contato que estabe- 
lecem e os seus padrões de evitação" (Greve, 1996, p. 195).

\section{DESCRIÇÃODAS ATIVIDADES}

\section{Histórico}

A coordenação do Centro de Extensão da Faculdade de Medicina da Universidade Federal de Minas Gerais, no desenvolvimento de seu trabalho ambulatorial junto a pacientes diabéticos e hipertensos em alguns Centros de Saúde Pública de Belo Horizonte, solicitou um trabalho conjunto com o Departamento de Psicologia da referida Universidade. A proposta foi no sentido de oferecer atendimento psicológico àqueles pacientes com dificuldades emocionais que, apesar de submetidos ao tratamento adequado, não demonstravam uma evolução clínica satisfatória.

As atividades desse projeto de extensão foram desenvolvidas no Centro de Saúde São Marcos e Centro de Saúde da Cachoeirinha, em Belo Horizonte, no período de setembro de 1995 a junho de 1997. A equipe era formada pela professora autora do trabalho, por alunos do curso de Psicologia e pelos profissionais envolvidos no trabalho com grupos de diabéticos e hipertensos nos Centros de Saúde (CERSAM): as gerentes administrativas, assistente social, fisioterapeuta, auxiliares de enfermagem, psicólogo e médico.

Todas as atividades realizadas pelos estagiários foram acompanhadas através de supervisão semanal durante o período da atividade de extensão. O espaço da supervisão era utilizado para discussão e reflexão dos atendimentos e situações ocorridas ao longo do trabaIho, bem como para estudo de textos sobre temas afins.

Considerando-se ser a clientela atendida pertencente a uma classe social menos favorecida, possuidora de dificuldades de ordem sócio-econômica, com baixo nível de es- colaridade, cujas necessidades básicas nem sempre são atendidas, houve um cuidado em levar tais características em consideração na elaboração e consecução das atividades desenvolvidas, especialmente no modo como a psicoterapia de grupo foi divulgada aos pacientes.

\section{Grupos Informativos}

Houve um período anterior à psicoterapia de grupo propriamente dita, cujo objetivo foi a apresentação do trabalho da Psicologia e a oportunidade de divulgar a proposta do grupo terapêutico, inclusive enfatizando a diferença de seus objetivos em relação aos dos grupos já existentes nos CERSAMs, os quais eram frequentados pela maioria dos pacientes diabéticos e hipertensos.

Neste sentido, as atividades se iniciaram com a participação das alunas nos grupos informativos de diabéticos e de hipertensos, em ambos os CERSAMs. Estes se configuravam em grupos abertos, homogêneos (compostos exclusivamente por pacientes portadores somente de diabetes ou hipertensão arterial de ambos os sexos), com realização semanal, duração aproximada de 90 minutos, coordenado por um profissional do Centro de Saúde envolvido com o tratamento de diabéticos e hipertensos. Cada estagiário de psicologia participou de, pelo menos, um grupo de diabéticos e um de hipertensos em cada um dos CERSAM.

O objetivo desses grupos de informação era esclarecera os participantes em que consiste a doença, suas várias implicações, procedimentos a serem adotados pelos pacientes, além de oferecer um espaço para troca de experiência entre os próprios pacientes. As palestras, de cunho informativo, eram proferidas por profissionais de diversas áreas, abordando desde aspectos particulares da doença, até dicas de receitas culinárias apropriadas para a doença em questão, buscando num outro plano, favorecer o engajamento do paciente em seu processo de evolução clínica. 
É importante ressaltar que o tema de tais grupos sempre esteve vinculado à doença (diabetes ou hipertensão arterial), tanto em termos de informação, quanto de alternativas e sugestões para lidar melhor com ela. Temas referentes à vida pessoal de cada um dos pacientes não eram abordados.

Os grupos informativos também se configuraram numa oportunidade para discriminar pacientes indicados para a psicoterapia, permitindo uma triagem inicial junto aos seus participantes.

\section{Entrevistas de Triagem}

A etapa seguinte consistiu na realização de entrevistas de triagem pelos estagiários da Psicologia, como objetivo de selecionar pacientes interessados na participação dos grupos psicoterapêuticos. Tais entrevistas eram individuais e com marcação prévia. As pessoas se inscreviam por iniciativa própria, devido ao interesse em fazer psicoterapia, ou mediante o encaminhamento de outro profissional do CERSAM.

Os critérios para seleção foram aqueles sugeridos na literatura sobre psicoterapia de grupo e a única exigência foi a de que os grupos se formassem exclusivamente por pacientes diabéticos e/ou hipertensos (houve procura por parte de outras pessoas freqüentadoras do Centro de Saúde).

\section{Grupos de Psicoterapia}

Quanto aos grupos psicoterapêuticos, foram realizados seis grupos de atendimento, dois em cada CERSAM, com freqüência semanal e duração de 90 minutos. Participaram pessoas de ambos os sexos e mistos quanto à patologia (isto é, havia tanto diabéticos quanto hipertensos num mesmo grupo).

Apesar de compostos por pessoas portadoras de uma doença comum, não giravam necessariamente em torno da doença, embora ela tenha inicialmente servido como um tema comum a todos, e por isso facilitado o contato entre as pessoas. Aos poucos, o vínculo entre elas foi se estabelecendo e questões de cunho mais pessoal foram sendo trazidas para o setting grupal.

Coerente com a proposta de psicoterapia de grupo adotada, um de seus principais objetivos foi oferecer um espaço onde as pessoas pudessem refletir sobre a doença, sobre a repercussão que ela teve na sua vida, nas suas relações conjugais, familiares e sociais. $O$ foco era a pessoa como um todo, o que certamente incluía não só a doença, mas também outros aspectos de sua vida e as questões que emergiam no espaço do grupo.

Outro objetivo foi buscar o desenvolvimento das potencialidades de cada pessoa. A tônica do trabalho terapêutico foi favorecer a conscientização das situações vivenciadas pela pessoa e pelo grupo, de modo que fosse possível o desenvolvimento de recursos para lidar com as experiências, o reconhecimento dos limites e o fortalecimento do auto-apoio, aumentando, assim, a auto-estima. Com isso, o foco das intervenções incidiu sobre a exploração das experiências e sentimentos trazidos pelos participantes.

Cabe ressaltar que ocorreu uma certa demora na formação dos grupos. Inicialmente, várias pessoas se mostraram interessadas e necessitadas de um acompanhamento psicoterapêutico, mas não compareciam às sessões ou participavam de umas poucas e desistiam, alegando impossibilidades pessoais ou incompatibilidade de participar de dois grupos simultaneamente (do informativo e do psicoterapêutico). Entretanto, uma vez consolidada a formação dos grupos, as pessoas se engajaram no processo psicoterapêutico. À medida que o vínculo entre elas ia se fortalecendo, mostravam-se mais encorajadas a partilhar com os demais membros seus pensamentos e sentimentos. 


\section{DISCUSSÃO}

Um dos objetivos do trabalho ter se iniciado pela participação dos estagiários nos grupos de informação se deu em função da necessidade de esclarecimento sobre o papel do psicólogo e a proposta de trabalho no Centro de Saúde, além de propiciar contato mais próximo com a clientela a ser atendida. Esperava-se com isso facilitar o entendimento sobre o novo espaço terapêutica oferecido e, conseqüentemente, sua formação e continuidade. Tal objetivo foi alcançado, pois a maior parte dos pacientes atendidos nos grupos psicoterapêuticos também participava dos grupos informativos.

Nessa primeira etapa, a entrada do estagiário de Psicologia nos grupos de informação facilitou a catarse e a elaboração dos sentimentos dos pacientes (num nível mais superficial), visto que ao falarem da doença, os pacientes, em muitos momentos, ficavam profundamente mobilizados e nem sempre os profissionais das demais áreas presentes no grupo sabiam lidar com tais manifestações de forma adequada.

Ao se configurarem numa oportunidade para troca de experiências entre seus membros, tais grupos favoreceram os mecanismos de identificação e empatia , possibilitando então o pensar sobre a doença em si e sobre como ela era vivida por cada um. À medida, por exemplo, que um paciente expressava suas fantasias sobre a doença com os demais membros do grupo e que isso era trabalhado, não apenas em termos de esclarecimento, mas também de suporte emocional, o nível de ansiedade dele e de outros cujas fantasias eram semelhantes se dissipava, favorecendo um bem-estar entre o grupo.

Outro benefício da participação do profissional da área de Psicologia nestes grupos foi a divulgação do trabalho proposto (formação de grupos de psicoterapia) e o esclarecimento sobre o papel do psicólogo, muitas vezes confundido como o "profissional que trata de gente louca". Isso se deu tanto na experiência junto aos grupos informativos, quanto na palestra proferida, onde foi exposta uma breve descrição do que vem a ser o trabalho psicológico, como os fatores emocionais podem influenciar os sintomas físicos e quais as propostas de atuação do psicólogo clínico e da psicoterapia de grupo. A partir de então, verificou-se uma maior solicitação dos pacientes em relação aos serviços oferecidos pela Psicologia.

$O$ atendimento psicológico realizado através da psicoterapia de grupo demonstrou ter favorecido uma melhora significativa no bemestar dos pacientes que a ela se submeteram, o que parece ter se refletido, conforme dito anteriormente, no seu quadro clínico geral. Apesar de não ter sido realizada avaliação quantitativa sobre a melhorados pacientes diabéticos e hipertensos submetidos à psicoterapia de grupo, foi possível verificar, tanto no relato deles, quanto no de alguns membros da equipe, que tais pacientes, em maior ou menor grau, apresentaram maior controle emocional e mais responsabilidade nos cuidados para consigo mesmo, o que demonstrou ter favorecido sua evolução clínica. Entretanto, algumas considerações sobre o desenrolar do trabalho se fazem pertinentes.

Em muitos momentos, algumas pessoas verbalizaram que o simples fato de falar sobre os seus problemas e serem ouvidas por alguém interessado em ajudá-las era suficiente para proporcionar algum alívio. Também se mostraram fatores benéficos o contato com a própria experiência e com os recursos de que passaram a dispor para lidar melhor com eles, sinalizados tanto pelas psicoterapeutas quanto pelo grupo. Por outro lado, a constatação de que um determinado problema não era exclusividade sua, pois outros também o experimentavam de forma diferente, serviu para amenizar a ansiedade e ampliar o leque de possibilidades do cliente em relação a ele. Verificou-se, com isso, uma troca de vivências, onde cada um pôde aprender com a experiência do outro. 
Tais resultados foram coerentes com a proposta de Ulman (1996) de que, dos onze fatores terapêuticos característicos da psicoterapia de grupo propostos por Yalom (1995), a catarse, a universalidade, a transmissão de informações, a instilação de esperança, a aprendizagem social e o comportamento imitativo são os mais presentes no trabalho com pacientes portadores de comprometimento orgânico.

Foi constatado também o avanço dos pacientes ao longo do processo terapêutico. Podee afirmar que a psicoterapia de grupo provocou a emergência de temas conflitantes, o foco nas emoções e nos impasses de cada um e do grupo como um todo, bem como a ampliação da auto percepção de cada pessoa sobre sua experiência da situação em questão. Com isso, o trabalho desenvolvido a partir da abordagem gestáltica demonstrou ser uma experiência positiva em relação à ampliação do contato da pessoa consigo mesma e ao desenvolvimento de recursos para lidar com suas situações de vida (incluindo suas possibilidades e limitações).

Nem sempre isso se deu numa atmosfera de tranqüilidade, mas, ao contrário, houve momentos de intensa carga emocional. Entretanto, apesar das peculiaridades de cada membro do grupo, da diversidade de opiniões e das diferentes habilidades em lidar e respeitar a variedade de pensamentos, sentimentos, crenças e ações das demais pessoas do grupo, houve um clima favorável à reflexão dos temas emergentes e à elaboração, pelo menos parcial, das vivências que se seguiram.

Tais resultados ratificam as proposições expostas na revisão da literatura sobre a eficácia da psicoterapia de grupo no crescimento pessoal de seus membros em função de suas características peculiares (Campos, 1992; Greve, 1996; Melo Filho, 1997; Ribeiro, 1994; Rogers, 1987; Yalom, 1995).

Além disso, no atendimento psicoterapêutico a esta clientela específica, foi possível confirmar a importância da ênfase na expressão de seus sentimentos e a busca de novas alternativas frente às situações vivenciadas para que fossem possíveis alterações significativas na dinâmica das pessoas, conforme proposto por Campos (1992b).

Avaliado de uma perspectiva diferente, o trabalho se configurou numa experiência positiva não somente para a clientela participante, mas também para os estagiários envolvidos, que tiveram a oportunidade de realizar o atendimento na modalidade de psicoterapia de grupo em instituições públicas de saúde. A maior parte da prática clínica dos alunos ocorre nos moldes do atendimento em consultório particular. A atuação em Centros de Saúde, com clientes de uma classe social menos favorecida e em contato com outros profissionais, resultou numa excelente experiência para a sua formação. Buscou-se torná-los mais sensíveis às diferentes demandas desse tipo de clientela, desenvolvendo a noção de que profissionais humanizados, capazes de possuir um olhar contextualizado sobre a pessoa prestes a ser atendida e de desenvolver um trabalho integrado estão mais aptos a prestar um serviço de melhor qualidade à comunidade. Na prática, ficou evidente que nem sempre isso é fácil.

A tentativa de desenvolver um trabalho interdisciplinar junto a profissionais de outras áreas também foi uma grande fonte de experiências. Inúmeras vezes foram discutidas na supervisão não somente a aplicação dos aspectos teóricos envolvidos na prática, mas também os entraves típicos do trabalho em instituição, questões referentes ao trabalho do psicólogo junto a outros profissionais, às relações entre médico, paciente e demais profissionais da área de saúde.

Em alguns momentos, a atuação junto à equipe interdisciplinar deixou a desejar, especialmente em relação ao não envolvimento de alguns médicos, os quais se recusaram a encaminhar pacientes para o grupo de psicoterapia por não acreditarem no trabalho do psicólogo. Porém, é importante ressaltar que ambas as 
gerentes dos Centros de Saúde deram total apoio ao trabalho da Psicologia. Outros profissionais, incluindo as assistentes sociais também se mostraram colaboradoras para com a participação da Psicologia junto aos pacientes eà equipe.

Outro aspecto que deu margem à reflexão foi a imagem distorcida entre os próprios profissionais da área de saúde acerca do papel do psicólogo. Houve situações em que, num grupo informativo, por várias vezes, uma profissional de outra área invadiu o espaço de atuação da Psicologia, levando à discussão entre a própria equipe sobre o delineamento de papéis pertinentes a cada profissional.

A avaliação dos resultados obtidos durante as atividades demonstra um saldo positivo, especialmente junto aos pacientes. Entretanto, a experiência demonstrou também que, em trabalhos desse tipo, o psicólogo deve atuar também junto à equipe médica, buscando esclarecer ao máximo o seu papel e sobre as resistências que porventura surjam em relação ao seu trabalho. A aceitação do psicólogo por parte dos profissionais da Saúde, especialmente os médicos, é de suma importância para a aderência dos pacientes aos grupos terapêuticos, visto que o paciente chega ao Centro de Saúde em busca do atendimento médico e tem as recomendações desse profissional como forte referência para si.

\section{REFERÊNCIAS BIBLIOGRÁFICAS}

AMARAL, V. L. A. R. \& YOSHIDA, G. O. A psicologia como profissão daárea da saúde, a prática, a supervisão e a pesquisa: Relato de uma experiência. Em: Estudos de Psicologia, vol. 10, № 3, 85-94,1993.

BOARIM, M. L. Estágio em Posto de Saúde: Prática e reflexão. Em: Psicologia, Ciência e Profissão, ano 9, 2:27-30,1989.

CAMPOS, E. P. Aspectos psicossomáticos em cardiologia. Em: J. Melo Filho, Psicossomática Hoje, Porto Alegre: Artes Médicas, 1992.
CAMPOS, E. P. O paciente somático no grupo terapêutico. Em: J. Melo Filho, Psicossomática Hoje, Porto Alegre: Artes Médicas, 1992.

CARVALHO, R. M. L. L. Psicologia e psicanálise numa instituição pública de saúde. Em: Estudos de Psicologia,vol 14, № 1,3-14,1997.

CARVALHO, C. V. \& SILVA, L. C. Atuação de psicólogos na Saúde Pública: Dificuldades e possibilidades de trabalhos com grupos. Em: Psicologia, Ciência e Profissão, 2-3: 2023,1990.

GINGER, S. \& GINGER, A. Gestalt: Uma Terapia do Contato, São Paulo: Summus, 1995.

GREVE, D. W. Psicoterapia gestáltica de grupo. Em: H. I. Kaplan \& B. J. Sadock (org.) Compêndio de Psicoterapia de Grupo, 3a ed., Porto Alegre: Artes Médicas, 1996.

ISMAEL, S. M.C.A psicologia e o hospital. Em: InsightPsicoterapia, ano VIII, 85:22-23, 1998.

MARTINS, A. E. O. A concepção de homem na Gestalt-terapia e suas implicações no processo psicoterápico. Em: Revista do I Encontro Goiano de Gestalt-terapia, vol I, 1: 4771,1995 .

MELO FILHO, J. Grupoterapia com pacientes somáticos. Em: L. C. Osório. Como TrabaIhamos com Grupos, Porto Alegre: Artes Médicas, 1986.

Grupoterapia com pacientes somáticos: 25 anos de experiência. Em: D. Zimerman \& L. C. Osório. Como TrabaIhamos com Grupos, Porto Alegre: Artes Médicas, 1997.

PERLS, F.Abordagem Gestálticae Testemunha Ocular da Terapia, Rio de Janeiro:Zahar, 1977.

PERLS, F., HEFFERLINE, R. \& GOODMAN, P. Gestalt-terapia, São Paulo: Summus, 1995.

RIBEIRO, J. P. Gestalt-terapia: Refazendo um Caminho, São Paulo: Summus, 1985.

Gestalt-terapia:O Processo Grupal: Uma Abordagem- Fenomenológica da Teoria do Campo e Holistica, São Paulo: Summus, 1994. 
ROGERS, C. Grupos de Encontro, 5a ed., Porto Alegre: Artes Médicas, 1987.

SILVA, C. O. Trabalho e subjetividade no Hospital Geral. Em: Psicologia: Ciência e Profissão, ano 18, n 2, 26-36, 1998.

SILVA FILHO, N. Uma reflexão acerca da prática clínica em instituições hospitalares. Em: Estudos de Psicologia, vol 13,n 3, 3-9,1996.
TELLEGEN, T. A. Gestalt e Grupos: Uma Perspectiva Sistêmica, São Paulo: Summus, 1984.

ULMAN, K. H. Psicoterapia de grupo com os fisicamente enfermos. Em: H. I. Kaplan \& B. J. Sadock (org.) Compêndio de Psicoterapia de Grupo, 3eed., Porto Alegre: Artes Médicas, 1996.

YALOM, I. D. The Theory and Practice of Group Psychotherapy, 4th ed., New York: Basic Books, 1995. 